\title{
Enunciación
}

\section{La oralidad: su repercusión para la ciencia jurídica y la enseñanza del Derecho}

\author{
Orality: its repercussion for the juridical science and the teaching of law
}

\author{
Lisett Daymaris Páez Cuba*
}

\begin{abstract}
Resumen
El sistema oral, defendido por las tendencias contemporáneas, reporta beneficios loables para la impartición de justicia y, por ende, para la enseñanza del Derecho. El presente estudio sobre la oralidad es resultado de una intervención pedagógica en la Universidad de Pinar del Río con estudiantes de tercero, cuarto y quinto años de la carrera de Derecho, durante el periodo 2017-2019, en Cuba. El artículo tiene como objetivo argumentar la repercusión de la oralidad para la ciencia jurídica y para la enseñanza del Derecho en el ámbito universitario. La investigación es de tipo cualitativo y emplea la metodología de investigación sociojurídica, con la utilización de métodos teóricos y empíricos, como el histórico-jurídico, el jurídico-comparado, el de análisis-síntesis e inducción-deducción, el análisis de contenido, la observación científica y la entrevista grupal. La integración de los métodos y el abordaje de sus fundamentos teóricos permitieron obtener como resultados esenciales: la determinación de la oralidad como principio jurídico de carácter general para el Derecho Procesal y la propuesta de los juegos de roles de juicios orales como métodos de enseñanza problémica para enseñar a litigar. En el estudio realizado se muestran buenas prácticas validadas al desarrollar la simulación de tres juicios orales representados por estudiantes de la carrera de Derecho de la Universidad de Pinar del Río.
\end{abstract}

Palabras clave: derecho, juegos de roles, método de enseñanza, oralidad, principio jurídico.

\begin{abstract}
The oral system, defended by contemporary trends, provides laudable benefits for the administration of justice and, therefore, for the teaching of Law. The present study on orality is the result of a pedagogical intervention at the University of Pinar del Río with the third, fourth and fifth level students of the Law degree, during the period 2017-2019, in Cuba. The objective of the article is to argue the repercussion of orality for juridical science and for the teaching of Law in the university environment. The research is qualitative and uses socio-legal research methodology, using theoretical and empirical methods such as historical-legal, comparative-legal, analysis-synthesis and induction-deduction, content analysis, scientific observation and group interview. The integration of the methods and the approach of their theoretical foundations allowed to obtain as main results: the determination of orality as a general juridical principle for Procedural Law and the proposal of role plays of oral trials as problem teaching methods to teach litigation. The study carried out shows good practices validated when developing the simulation of three oral trials represented by students of the Law studies at the University of Pinar del Río.
\end{abstract}

Keywords: law, role plays, teaching method, orality, legal principle.

Doctora en Ciencias Pedagógicas. Profesora de Derecho y vicedecana de Investigación y Posgrado de la Facultad de Ciencias Sociales y Humanidades. Universidad de Pinar del Río, Cuba. Correo electrónico: lisypc87@gmail.com

Cómo citar: Páez Cuba, L. D. (2020). La oralidad: su repercusión para la ciencia jurídica y la enseñanza del Derecho. Enunciación, 25(2), 206-219. https://doi. org/10.14483/22486798.16005

Artículo recibido: 9 de marzo de 2020; aprobado: 11 de agosto de 2020 


\section{Introducción}

El juicio oral y público aparece como práctica reconocida por los sistemas judiciales modernos, a la par de los más avanzados estudios teóricos sobre oratoria forense. De tal forma, las relaciones entre oralidad y derecho, si bien no cuentan con amplia profusión investigativa, sí derivan importantes estudios tanto lingüísticos como jurídicos. Por ende, dilucidar aspectos de esta relación representa un imperativo no solo para el Derecho como ciencia, sino también para su didáctica, en aras de perfeccionar el proceso de enseñanza/aprendizaje del estudiante de leyes.

La investigación parte de formular un interrogante inicial: ¿Qué repercusión tiene la oralidad para la ciencia jurídica y para la enseñanza del Derecho en las universidades? Abocados a encontrar una respuesta al respecto, se analizan las bases teóricas de la oralidad desde la ciencia del Derecho, lo cual permite atribuirle el carácter de principio jurídico. Su expresión, a través de la oratoria forense en la configuración del alegato judicial, le hace susceptible de implementación también para el desarrollo de juegos de roles, los cuales constituyen métodos de enseñanza problémica trascendentales para la carrera de Derecho.

A decir de Prieto (2001), el Derecho es un fenómeno social complejo, que designa un comportamiento social condicionado por elementos socioeconómicos, políticos, ideológicos, culturales, con un contenido axiológico. Es un instrumento para declarar e imponer valores, conjunto de principios sustentadores de las normas dentro del ordenamiento legal. Por consiguiente, el ejercicio del Derecho como acto propiamente normativo, axiológico y social, requiere de una adecuada comunicación de los argumentos jurídicos a través del lenguaje oral. De hecho, "se parte de considerar que argumentar constituye una habilidad cognitivo-lingüística inherente al ejercicio de la profesión jurídica" (Núñez y Páez, 2018, p. 345). $\mathrm{Y}$ aunque muchos estudiantes consideran resolver problemas complejos presuponiendo que ya saben argumentar, lo cierto es que los resultados investigativos precedentes muestran un bajo desempeño argumentativo en el alumnado (Rodríguez y Giraldo, 2019).

En la historia del Derecho, los procesos argumentativos orales datan del periodo de la monarquía romana, específicamente de la etapa referida al sistema de las acciones de la ley, o legis actions, caracterizado por su oralidad, inmediatez y concentración, a decir de Casanueva (2010). Este panorama cambió con la instauración de "la appeIlatio, momento en el cual, como consecuencia de la necesidad de revisión, por parte del órgano jurisdiccional superior, de lo actuado por el inferior, se hizo necesaria la protocolización de los procesos" (Gimeno, 1981, pp. 222-223).

El resurgimiento de la escritura se debe en gran medida a la necesidad de tener constancia de las actuaciones judiciales, más que como mera acción recordatoria de lo acaecido en el juicio, como medio para la posterior interposición de recursos y medios de impugnación. Esta idea, centrada en hacer constar las actuaciones por escrito, pronto adquiriría preeminencia, lo cual fue dando paso a la escritura hasta contar con un proceso judicial escrito de origen medieval.

Ciertamente en la Edad Media hubo un retroceso de la praxis jurídica en cuanto a la oralidad, debido a las particularidades del propio sistema inquisitivo, caracterizado por la secretividad. La recuperación de la oralidad en el ámbito forense no ocurre hasta el siglo XIX, como mérito de Francia producto de la codificación napoleónica, a través de los Códigos de Procedimiento Civil y Penal, de 1806 y 1808, respectivamente. No obstante, sería el jurista italiano Giuseppe Chiovenda quien iniciara, a fines del siglo XIX y principios del XX, un ejercicio reivindicatorio a modo de campaña doctrinal a favor de la oralidad, según Montero (2006).

El propio decurso del pensamiento jurídico llevaría a la conclusión de que la oralidad constituiría una garantía para la impartición de justicia, en 
especial por la posibilidad que ofrece de enfrentamiento directo de los protagonistas del conflicto en una sola actuación jurisdiccional, a criterio de González (1996). Así, los códigos procesales contemporáneos coinciden al instituir los juicios orales como espacios oficiales para solucionar los conflictos sociales que trascienden al escenario judicial, sin desdecir el inconveniente que pudiera representar el desempeño oral de determinados procesos por su naturaleza jurídica.

Lo cierto es que, en la actualidad, tanto juristas de oficio, catedráticos como investigadores del Derecho identifican la oralidad como principio jurídico del procedimiento, criterio seguido por autores como Prieto-Castro (1964); Cappelletti (1972); Chiovenda (1977); Couture (1981); Binder (1993); Ferrajoli (1995); Nieva (2010); Suñez, González y Urra (2012); Mendoza (2013), y Velazco (2015).

A su vez, la oralidad impacta en la didáctica del Derecho, pues la mayoría de las materias impartidas en esta carrera universitaria permiten que el estudiante emita y reciba más información oral que escrita. De ahí se deriva la necesidad de intervenciones didácticas en el aprendizaje de los procesos que conducen a producir un discurso hablado, puesto que el alegato judicial, al ser un uso oral elaborado o formal, requiere de una atención especial, al constituir por antonomasia la expresión jurídica más concreta de la oralidad.

En este sentido, los estudios teóricos sobre oralidad resultan actuales y pertinentes en dos dimensiones: para cientistas jurídicos y para didactas del Derecho. Por tanto, el presente artículo tiene como objetivo argumentar la repercusión de la oralidad para la ciencia jurídica y para la enseñanza del Derecho en las universidades.

En el presente documento se justifica la selección de la metodología empleada, se examinan los referentes teóricos que sustentan la investigación y se discuten los resultados arribados; todo lo cual permitió validar la implementación de los juegos de roles orales como forma de intervención pedagógica en la carrera de Derecho.

\section{Metodología}

Para la conceptualización de la oralidad, su determinación como principio procesal de la ciencia jurídica y su aplicación a los juicios penales simulados en la carrera de Derecho en Pinar del Río, se empleó la metodología de investigación sociojurídica, propuesta por Villabella (2012). La investigación, de tipo cualitativo, utiliza métodos teóricos y empíricos para la concreción de los resultados científicos ofrecidos. Entre ellos se encuentran el histórico-jurídico, el jurídico-comparado, el de análisis-síntesis e inducción-deducción, el análisis de contenido, la observación científica y la entrevista grupal.

Los métodos teóricos empleados en la investigación constituyen procedimientos del razonamiento lógico que permiten profundizar en aquellas dimensiones del objeto que no se pueden observar directamente, por lo que requieren un mayor nivel de abstracción. Estos posibilitaron el abordaje teórico de la oralidad, su definición, su análisis desde una perspectiva diacrónica en la rama jurídica y su relación directa con el ejercicio forense.

El método histórico-jurídico permitió analizar la evolución de la oralidad primaria hasta la oralidad secundaria, su tránsito por los modelos de enjuiciamiento, los que en su momento histórico -esencialmente medieval- abandonaron la oralidad, hasta que fueron retomados posteriormente. Este método permitió clasificar en etapas y tendencias la evolución de la oralidad, desde que se introduce en el campo del Derecho como aporte esencial del sistema de enjuiciar acusatorio, con falencias en el sistema inquisitivo, hasta llegar a la connotación contemporánea de considerarle un principio en materia procesal.

El método jurídico comparado, o de comparación jurídica, permitió contrastar la regulación jurídica de la oralidad desde el Derecho Procesal. Su finalidad estuvo dirigida a identificar semejanzas y diferencias en los ordenamientos jurídicos estudiados, de modo que los patrones comparativos 
aportasen referentes jurídicos a tener en cuenta con posterioridad. Comparativamente se analizaron los Códigos Procesales Penales de Argentina y Guatemala, el del Distrito Federal de México, la Ley de Enjuiciamiento Criminal española y la Ley de Procedimiento Penal cubana. Su revisión mostró como resultado convergente la regulación explícita -o implícita, en ocasiones- de la oralidad en el contenido jurídico de dichas normativas.

El método de análisis-síntesis favoreció el estudio de la oralidad de manera detallada, al descomponerle en sus partes y cualidades para el análisis teórico, y al unificar estas de acuerdo con sus elementos comunes, logrando la concreción de la oralidad como principio jurídico. La inducción-deducción a su vez permitió razonar las particularidades y generalidades de la oralidad y sus manifestaciones en los ámbitos científicos del Derecho y de la didáctica. Esta perspectiva reveló la pertinencia de insertar de manera general la oralidad en los sistemas judiciales y de manera particular en la enseñanza de la ciencia jurídica.

Como métodos empíricos se emplearon la observación científica y el análisis de contenido. Este último estuvo orientado a conocer, de forma auténtica y confiable, el estado del arte de la oralidad en materia lingüística, jurídica y educativa, a partir del examen de las fuentes doctrinales y de los principales documentos normativos y curriculares de la carrera de Derecho. La observación científica permitió obtener información primaria sobre el empleo de la oralidad en el currículo de siete universidades (que incluye la Universidad de Pinar del Río, Cuba), teniendo en cuenta las asignaturas dedicadas al estudio de la oralidad y las experiencias acumuladas en el ámbito internacional en el desarrollo de los juegos de roles litigantes.

Como método empírico se aplicó además la entrevista grupal, dirigida a un total de 48 estudiantes de la carrera de Derecho, de los años académicos de tercero a quinto. Estos se distribuyeron de la siguiente forma: 11 estudiantes participantes en el juicio simulado en 2017, 22 alumnos en el de
2018 y 15 en el de 2019. La aplicación de este método permitió determinar las regularidades del proceso formativo de lo oral en la carrera de Derecho, y en particular analizar el impacto de los ejercicios simulados de juicios orales durante el periodo 2017-2019 en la Universidad de Pinar del Río, Cuba.

La integración de los métodos y el abordaje de los fundamentos teóricos permitieron sustentar la intervención pedagógica a través de los juegos de roles de juicios orales. La observación científica facilitó identificar detalles significativos en el proceso de enseñanza/aprendizaje de la oralidad jurídica, en particular lo relativo a la asunción los roles procesales, la evolución en el uso del lenguaje técnico y la significación de las interacciones lingüísticas logradas durante la presentación de los alegatos orales.

\section{Marco teórico}

El uso oral del lenguaje ha sido objeto de múltiples investigaciones en Ciencias Sociales, pues este "constituye una actividad social fundamental, ineludible cuando se estudia el funcionamiento de los grupos humanos" (Abascal, 2004, p. 92). Desde los más antiguos orígenes de la oralidad primaria hasta la aparición de la imprenta que conlleva a la importante influencia de la escritura y así da paso a la oralidad secundaria, siempre los estudios de oralidad han sido inherentes al género humano. Su relevancia se basa precisamente en que "la oralidad es la forma primigenia y natural del lenguaje, y es además la que domina nuestra vida cotidiana" (Areta, 2007, p. 317).

Variados resultan los estudios teóricos relativos a la oralidad como constructo empleado en la literatura especializada (Olson y Torrance, 1995; Ong, 1996; Abascal, 2004; Núñez, 2003, 2011; Gutiérrez y Rosas, 2008; Lomas, 2014). En general, estos autores consideran que se trata de un tipo de lenguaje empleado para la comunicación oral, el cual no es objeto exclusivo de las ciencias del 
lenguaje, sino de múltiples disciplinas científicas abocadas a los estudios sociales y antropológicos.

La oralidad es definida como "una capacidad comunicativa que configura modos de percibir, de pensar y, por supuesto, de expresar el mundo" (Núñez, 2003, p. 218). Es entendida también por esta autora [Núñez] como un fenómeno interdisciplinar que puede analizarse desde las dimensiones técnica y humanística, lingüístico-discursiva, cultural o antropológica, pedagógica y curricular. De hecho, con certeza asevera que la oralidad

[...] se presenta, pues, como un concepto poliédrico, de múltiples caras y también de múltiples aristas, difícil de definir. Sin duda, se trata de un constructo, de un objeto conceptual, pero fuertemente vinculado tanto a procesos cognitivos como a procesos físicos y sociales. (Núñez, 2011, p. 137)

Por consiguiente, se deduce que la oralidad repercute en disímiles ámbitos, dentro de los cuales se encuentra precisamente el jurídico. De manera el análisis de los alegatos judiciales expuestos en audiencias públicas constituye terreno fértil para el estudio de lo oral, particularmente de la oratoria forense, cuyos antecedentes datan de las configuraciones primigenias de la oratoria y la retórica clásicas.

A decir de Mortara (1988, p. 11), "actualmente el crecimiento de los estudios retóricos ha originado sugerentes alianzas: ante todo con los estudios jurídicos, en la línea de la más antigua vocación retórica". En ese sentido, oralidad y Derecho muestran un nexo ineludible, desde los propios orígenes de la retórica (donde encuentra sustento la argumentación jurídica) hasta los más modernos enfoques de la oratoria judicial (cuyo objeto lo constituye el discurso forense).

La oratoria forense aparece entonces como una expresión del binomio oralidad/derecho. La oralidad en el ámbito jurídico alude por excelencia al desarrollo del juicio oral en el foro, o lo que es igual: la argumentación oral en las audiencias públicas. A consideración de Ossorio (2000), la oratoria forense es:
La impuesta por la auténtica oralidad procesal y se despliega ante los tribunales de justicia, en las vistas o audiencias, por las partes rara vez, y por los letrados que las representan, para exposición del caso, presentación de pruebas y fundamentos jurídicos en pro de la causa por la que se alega. (p. 658)

La oratoria forense asume variadas configuraciones, en dependencia de los ordenamientos jurídicos y escenarios judiciales donde se desarrolle, pero en cualquier sistema de Derecho constituye expresión de la actividad del litigante; de ahí la importancia de los estudios de la oralidad para la ciencia jurídica. Su empleo es una cuestión asociada al análisis del discurso del fiscal o del abogado, quienes presentan a los tribunales de justicia la teoría del caso basada en los hechos, el material probatorio y los fundamentos jurídicos, con el fin de obtener sentencias condenatorias o absolutorias a su favor.

A consideración de Baytelman y Duce (2004, p. 220), "el discurso forense o alegato es el primer y único ejercicio argumentativo en todo el juicio", este constituye el debate oral exclusivo de los litigantes. La oratoria judicial o forense es la que permite que un juez o tribunal establezca conclusiones basadas en ese alegato del orador. Por ende, para los tribunales de justicia, la presentación de la tesis de los letrados es sustancial en el desarrollo de las vistas o audiencias, donde el empleo de la oralidad resulta consustancial al propio juicio.

El abordaje precedente del marco teórico de la oralidad permite reflexionar sobre su trascendencia para la ciencia del Derecho, cuya materialización se logra a través del ejercicio de la oratoria forense en los tribunales de justicia. Entre tanto, el desempeño jurídico en juicios orales tendrá mayor calidad en la medida que el jurista litigante logre desplegar un adecuado acto retórico con empleo de la argumentación jurídica y las técnicas de acción oratoria, aspectos que deben ser intencionados en la enseñanza del Derecho. 


\section{Resultados}

A continuación, se presentan los resultados de la investigación, mediante una descripción de dos postulados fundamentales: la determinación de la oralidad como principio jurídico y la propuesta de los juegos de roles de juicios orales como métodos de enseñanza problémica. Esta dualidad permite visualizar la polivalencia de la oralidad, en cuanto -en el presente estudio- se revela su utilidad para juristas y didactas.

\section{La naturaleza jurídica de la oralidad: un principio para el Derecho}

Un importante punto de análisis en la doctrina forense consiste en determinar la naturaleza jurídica de la oralidad, partiendo de que esta es, para el Derecho, más que una mera categoría que expresa la forma del lenguaje. Resulta que, en el contexto actual, la oralidad cobra un nuevo significado como principio del procedimiento, que alcanza no solo a los implicados en el proceso, sino a los que asisten a los actos judiciales como forma de participación popular.

Un sector predominante de la comunidad jurídica de procesalistas considera la oralidad como un principio de carácter general en el proceso judicial. Teniendo en cuenta que un principio, a decir de Valle (2009), es aquel fundamento o idea rectora de algo, se puede deducir entonces que los principios jurídicos constituyen enunciados generales que evidencian determinada noción de justicia en una sociedad y sirven de sustento a las normas jurídicas. Así lo ratifican Suñez, González y Urra (2012) al considerar que la oralidad tiene carácter de principio rector dentro de los que informan el proceso judicial, todos ellos a su vez regidos por un megaprincipio del Derecho: la legalidad.

La rama del Derecho que estudia la oralidad como principio es el Derecho Procesal, materia encargada de concretar el ejercicio de los derechos subjetivos en la práctica judicial. Es el conjunto de normas, principios y categorías que evidencia la forma de ejecución de ese Derecho Sustantivo', ya sea penal, civil, administrativo u otro (Páez y Díaz, 2016). De tal forma el Derecho Procesal regula el procedimiento durante el cual deben cumplirse axiomas como la inmediación y la concentración, que a su vez son dos principios estrechamente vinculados al de oralidad, incluso derivados de esta, según Nieva (2010), quien argumenta el hecho de que:

La doctrina mayoritaria se refiere a la oralidad y a la escritura extrayendo unos principios que se derivarían de las mismas o "principios-consecuencia", siguiendo probablemente, una vez más, las enseñanzas de Chiovenda en este sentido. De esa forma, la inmediación, la concentración y la publicidad, serían consecuencia de la oralidad. (p. 14)

En este sentido, estudiar lo relativo a los principios del procedimiento judicial implica entender relaciones lógicas entre oralidad y publicidad, inmediación y concentración, aunque no necesariamente sean vínculos de dependencia exclusivos. A este criterio se suma Couture (1981), para quien el principio de oralidad alude a los actos procesales realizados a viva voz mediante audiencias; y aunque está presente en todas las etapas del proceso, su especial repercusión atañe a la fase del juicio oral, donde se practican las pruebas y se exponen los alegatos de las partes litigantes. La escritura, por su parte, opera para fases de mayor enjundia jurídica, como la presentación de escritos de iniciación de las partes, según Cappelletti (1972), u otros procedimientos de mero trámite, para los cuales la oralidad pudiera convertirse en un obstáculo para la economía procesal.

Con minucia, Velazco (2015) describe que la oralidad no se refiere estrictamente a la ausencia de escritura, toda vez que los actos jurídicos requieren, necesariamente, ser documentados; sino más bien, la oralidad como principio responde a

Mientras el Derecho Sustantivo tiene una función enunciativa, el Derecho Procesal o adjetivo es más ejecutivo, operativo, de formas. El Derecho Sustantivo es aquel que existe per se, para regular las relaciones jurídicas primarias, mientras que el Derecho Procesal está dirigido a complementar al sustantivo a través del procedimiento. 
una forma de desarrollar las audiencias públicas, donde prime el ejercicio oral del lenguaje técnico-jurídico propio de la abogacía. Así se reafirma el pensamiento de Abascal (2004), quien sostiene la idea que, paradójicamente, la relación entre la oralidad y la escritura no es antagónica, sino de interpenetración.

En el escenario jurisdiccional esta interrelación oralidad/escritura se concreta como un vínculo de interdependencia, en cuanto existen momentos del procedimiento que requieren ser manifestados en un documento escrito, como la demanda o la denuncia, los autos y providencias, los escritos de acusación y defensa, la sentencia; mientras que otras actuaciones complementarias tienen un carácter puramente oral, a saber: la exposición de los hechos, la práctica de pruebas y la presentación de los alegatos judiciales.

No existen contradicciones entre oralidad y escritura en materia jurídica, pues mientras la ley es escrita, el alegato para implementarla es oral; la sentencia es escrita, mientras la audiencia que tributa a su contenido es oral. De hecho, el empleo de la oralidad no implica la subrogación del documento escrito, sino más bien su preeminencia -de lo oral-por las ventajas jurídicas que ello reporta para la litigación. Y no es ni tan siquiera una cuestión de comodidad, pues la oralidad exige más capacitación técnica y mayor enfrentamiento en la comparecencia ante hechos que aparezcan de manera repentina; se trata más bien de lograr mayor efectividad en el proceso, al propiciar una interacción directa, pública y notoria entre los jueces y las partes.

Sin prescindir de la documentación escrita en su totalidad -como es obvio-, la regulación expresa y preeminencia de la oralidad ha sido la tendencia seguida por la legislatura jurídica, enarbolando la realización de audiencias públicas como habitual uso forense. Esta postura se valida también desde la academia según el criterio de autores como Rivero (2014, p. 83), quien afirma:

Prevalece la opinión de que un sistema, con predominio de la oralidad (modo normal de comunicación entre los seres humanos) y la publicidad, como el que se examina, posee más ventajas que inconvenientes, frente a sistemas más caracterizados por la escritura y el carácter secreto de las actuaciones. (p. 83)

El juicio oral ciertamente encuentra su nivel de máximo desarrollo cuando tiene carácter público, contradictorio, continuo y concentrado, al constituir la fase cardinal del proceso judicial. Para Ferrajoli (1995), el juicio oral es la etapa destinada a la práctica de las pruebas que sustentan la condena o la absolución de un individuo. Esta fase decisoria o de juicio es la predominante en los sistemas procesales modernos, donde rigen los principios esenciales de publicidad de los debates, inmediación, concentración, igualdad de las partes, contradicción y oralidad, todos los que conforman el modelo judicial de cuño acusatorio.

El sistema de enjuiciar acusatorio se caracteriza por el predominio de la oralidad y la publicidad, la participación popular y la libre apreciación de la prueba, contrario sensu del sistema inquisitivo, cuyo modelo de enjuiciamiento por registros ha ponderado desde sus inicios la escritura y la secretividad del proceso. No obstante, es válido aclarar, pese a las ventajas competitivas de lo oral, la tendencia moderna se orienta a la asunción del sistema mixto o acusatorio formal, donde no se desecha del todo la escritura, sino que prima la oralidad en fases como el juicio oral, en aras de enriquecer el debate judicial.

Por tanto, el principio de oralidad emerge como una característica del sistema acusatorio que tributa a la economía y la celeridad procesales, y a su vez deviene como vía para avalar ciertas garantías jurisdiccionales que un sistema netamente escrito no pudiera ofrecer. En ello radican sus principales ventajas, que apuntan a la interacción dinámica y directa de los sujetos en el proceso judicial.

La oralidad permite que la litis se fije de manera oral ante determinado tribunal a través del alegato, de manera que puedan suscitarse argumentos a favor y en contra del objeto del debate. Su finalidad 
esencial es precisamente el logro de celeridad, de inmediación, de una práctica de pruebas sometida a contradicción y de una exhaustiva argumentación de la teoría del caso. Así la oralidad en los procesos judiciales aparece como expresión de pleno debate jurídico, brindando la posibilidad de aportar razones que no fueron abordadas en el escrito inicial de las partes litigantes. La primacía de lo oral constituye, por ende, una práctica que cada día se abre camino con más fuerza en el ámbito de la judicatura.

La configuración de la oralidad como principio ya es una práctica reconocida por los sistemas judiciales contemporáneos, que la configuran esencialmente en el acto del juicio oral, mas no prescinden de ella en las demás etapas del proceso penal. Entre los ejemplos distintivos de esta propensión se encuentran los Códigos Procesales Penales de Argentina (1991), México (1934) y Guatemala (1992), como expresión del Derecho Procesal latinoamericano.

El desarrollo del juicio oral como institución jurídica sí está contemplado de manera mayoritaria en los Códigos Procesales Penales modernos, que incluyen a Cuba y a España, siendo precisamente el juicio oral una institución que esta última hiciera extensiva a la nación cubana por razones históricas. En consecuencia, tanto la Ley de Procedimiento Penal cubana, aprobada por la Asamblea Nacional del Poder Popular de Cuba en 1977, como la Ley de Enjuiciamiento Criminal española, en vigor desde 1882 y modificada en 2015, dedican los Libros IV y III respectivamente a regular los preceptos relativos a la celebración del juicio oral.

Grosso modo se puede afirmar que la oralidad se introduce en el campo del Derecho como aporte esencial del sistema de enjuiciar acusatorio. Su connotación contemporánea es tal que ha adquirido el rango de principio en materia procesal, que a su vez permite la realización de los fines judiciales y la materialización de las garantías del proceso. Su regulación jurídica expresa ofrece mayor celeridad, facilita la relación directa del juez con las partes y permite la concentración y unidad de acto. Su trascendencia al escenario de la litigación se concreta esencialmente a través de la oratoria forense, la cual es significativa para la obtención de una sentencia favorable al encartado o a la víctima. De tal manera, aunque en algunos fueros y ramas del Derecho opere la escritura, esta se armoniza necesariamente con el procedimiento oral.

\section{La implementación de la oralidad en la enseñanza del Derecho a través de los juegos de roles}

Incursionar en estudios sobre la oralidad no es nada fácil y hablar de su didáctica todavía lo es menos, según Pujol (1992), quien nos ofrece el punto de partida para vislumbrar un escenario complejo, mas no por ello inaccesible desde la ciencia del currículo. La oralidad, como fenómeno interdisciplinar analizado supra, tiene una dimensión curricular, que permite circunscribirla al ámbito de la interacción oral entre docentes y aprendices, y de manera particular insertarla en el sistema didáctico propio de la carrera de Derecho.

El examen de los resultados precedentes de la investigación permite dilucidar que los estudios jurídicos no pueden obviar un principio como la oralidad para su diseño curricular. El propio análisis del currículo jurídico comparado permite visualizar cómo diferentes planes de estudios internacionales han concretado materias como la Oratoria y otras como la Litigación y la Argumentación Jurídica, las que se han insertado incluso en el posgrado científico.

Algunos ejemplos de los referidos diseños curriculares enfocados a potenciar la oralidad en la enseñanza del Derecho, según Páez (2014), resultan: Ia Universidad Nacional Autónoma de México (UNAM); la Universidad Europea de Madrid; la Universidad de los Andes; la Universidad Michoacana de San Nicolás de Hidalgo, en México; la Universidad de Medellín, Colombia; y la Universidad de Harvard. En todas ellas se potencia la impartición de materias enfocadas a la formación 
de la competencia oral para el desempeño de los litigantes en los tribunales de justicia.

En Cuba, el actual plan de estudios E (de acuerdo con la designación alfabética de la quinta generación de planes de estudio en el país) permite una flexibilización para insertar otras materias complementarias al currículo obligatorio de la carrera de Licenciatura en Derecho. En la Universidad de Pinar del Río, por citar un ejemplo, además de las materias básicas de Derecho Procesal, se imparte la asignatura Oratoria como parte del currículo optativo-electivo, el cual potencia el empleo de métodos de enseñanza/aprendizaje activos orientados al desarrollo de lo oral.

En tal sentido, al analizar el pensamiento de Álvarez (1999, p. 23) cuando se refiere a la necesidad de "utilizar el método de la ciencia, como método fundamental de enseñanza y aprendizaje, y de trabajo", encontramos que los métodos para la enseñanza de la oralidad también deben ser considerados. Por ende, si la oralidad es un principio esencial del Derecho, lo es también para la enseñanza de esta ciencia en las universidades, en tanto los principios y métodos de la ciencia jurídica son aplicables además a la Didáctica del Derecho. Esta es una idea rectora en la investigación, por la manera en que trasciende la oralidad no solo al campo del Derecho (por cuanto es un principio jurídico), sino también a la enseñanza del Derecho (donde se puede emplear como método la simulación de juicios orales).

Entre los métodos de enseñanza favorecedores de la oralidad en los estudios universitarios del Derecho se encuentran los métodos problémicos, que incluyen los juegos didácticos creativos. Estos últimos, como asevera Álvarez (1999), tienden a profesionalizar la enseñanza. Su empleo favorece el aprendizaje activo y el desarrollo de estrategias metacognitivas que le permiten al estudiante reflexionar, controlar y direccionar su propio aprendizaje.

Los juegos didácticos creativos constituyen un vehículo idóneo para desarrollar la competencia oral del jurista. Así se destacan, de acuerdo con la clasificación brindada por Majmutov (1983), los juegos didácticos de carácter competitivo (olimpiadas y encuentros de conocimientos) y los juegos de roles profesionales u ocupacionales (análisis de casos e interpretación de papeles). Tanto los primeros -o sea, los juegos competitivos-, más enfocados a la dimensión extracurricular, como los segundos -los profesionales-, orientados a lo curricular, son una forma de interacción oral dialógica entre los propios estudiantes. Su materialización constituye el preludio -a título simbólicode la actividad profesional.

Una experiencia interesante resultan los juegos de roles particularizados a la carrera de Derecho, o lo que es lo mismo: los juegos de roles litigantes. Estas iniciativas "surgen como respuesta a la poca presencia de estrategias de enseñanza que fomenten una participación activa de los estudiantes" (Páez y Carballo, 2020, p. 19). Entre dichas alternativas se destacan los talleres de jurisprudencia, las clínicas jurídicas y los ejercicios de juicios simulados, o moot courts.

Esta idea del moot, o ejercicio de simulación, asociada al desarrollo de juegos de roles como métodos problémicos del proceso docente, ha sido extendida a varios sistemas educativos. El propio caso cubano es un ejemplo de ello, pues en 2013 se desarrolló el primer Concurso de Arbitraje Comercial Internacional, un ejercicio de simulación de carácter competitivo para resolver litigios comerciales. La defensa se realizó de forma escrita (presentando los Memoriales de Demanda y Contestación) y de forma oral (durante la audiencia arbitral). Participaron como evaluadores profesores de Derecho junto a árbitros internacionales y abogados en ejercicio. Se potenciaba así, desde opciones extracurriculares, la formación de la competencia oral en el jurista, orientada a su profesionalización.

En la Universidad de Pinar del Río también se han desarrollado los concursos de litigación durante el último quinquenio. Como parte de la 
presente investigación, se desarrollaron juicios orales simulados, en los cuales los estudiantes asumieron roles de jueces, fiscales y abogados defensores. Previamente se indicó la lectura de materiales, la observación de otros juicios en la sala judicial de la provincia y los entrenamientos previos. Posteriormente se desplegaron ensayos para la aprehensión de la metodología por parte de los aprendices.

Para la selección de los premiados se evaluó la competencia oral de los concursantes, el empleo de argumentos lógicos y emotivos en la estructuración del informe, el dominio del tema y el desarrollo de habilidades litigantes. La planificación de intervenciones orales formales dio lugar a interacciones lingüísticas significativas.

Una de las actividades curriculares desdoblada posteriormente con acierto resultó un juicio sobre el delito de "robo con violencia en las cosas e intimidación en las personas", con la participación de 11 estudiantes del cuarto año de la carrera, los cuales habían recibido la asignatura optativa Litigación en el curso 2017-2018. Como paso previo se hizo el análisis documental de la guía metodológica para la realización del juicio oral, puesta en vigor en Cuba desde 2011, como normativa complementaria a la Ley de Procedimiento Penal.

En este escenario se analizaron cuestiones relativas a las formalidades del juicio oral, los actos de iniciación, la práctica de pruebas, las conclusiones definitivas y alegatos, el derecho de última palabra del acusado y las particularidades de la culminación. Como resultado, los propios estudiantes desarrollaron por sí solos los roles de jueces, abogados y fiscales, e incluso comenzaron a identificarse con determinados modos de actuación profesionales. Así se develó el componente emotivo-afectivo y la predisposición estudiantil hacia la oratoria forense, pues "los casos prácticos comportan datos relevantes para el ejercicio del derecho, pero también implican muchas emociones de los sujetos involucrados en los mismos" (Narváez, 2019, p. 87); los cuales se identificaron -en este caso en particular- más con el rol de acusador que con el de abogado defensor.

Posteriormente, en 2018, tuvo lugar la representación relativa al Juicio del Moncada, en el Tribunal Provincial Popular de Pinar del Río. Participaron como asesores 8 docentes y 6 jueces penalistas, así como 22 estudiantes con diferentes roles de abogados, fiscales y jueces. Se simuló el proceso incoado en Santiago de Cuba por la causa 37 del año 1953, la cual juzgaba el delito de Actos contra los poderes constitucionales del Estado. "El objeto del debate lo constituyó precisamente el alegato La historia me abso/verá, que constituye la pieza oratoria más trascendental del siglo XX cubano" (Páez y Carballo, 2020, p. 24)

Dicha actividad requirió la participación activa del estudiantado en las disertaciones orales durante el debate judicial. En particular, el representante de Fidel Castro (principal acusado que ejerció su autodefensa) y el resto de los litigantes orales (representantes de los moncadistas) defendieron a ultranza sus posturas jurídicas. La relevancia de lo oral surgió durante la interacción dialógica lograda específicamente en las fases de práctica de pruebas y de presentación de alegatos. Este ejercicio tributó de manera significativa al desarrollo de habilidades litigantes, según Páez y Carballo (2020), y de forma especial -se agrega- al proceso formativo de habilidades oratorias propias de los actores judiciales.

Recientemente, en 2019, para dar continuidad a la investigación educativa relativa al impacto de la oralidad en la enseñanza del Derecho, se desarrolló la representación del Juicio de los Cinco Héroes cubanos injustamente encarcelados en Estados Unidos de América. Este ejercicio de simulación tuvo lugar en la provincia de Pinar del Río, con tributo significativo al desarrollo de habilidades litigantes en los aprendices. De hecho, la participación de 15 estudiantes del año terminal de esta carrera constituyó un referente para el desarrollo de la argumentación jurídica, el análisis exegético-analítico de la causa judicial radicada en el 
Distrito Federal de la Florida y el estudio comparado del sistema judicial norteamericano.

Esta representación judicial supera a las anteriores en la medida que rebasa la competencia jurisdiccional nacional para inmiscuirse en el estudio del derecho extranjero, y por ende, son frecuentes términos propios del uso oral anglosajón. Durante esta simulación jurídica se destaca además la asunción de expresiones que denotan cortesía, tales como: "distinguidos magistrados", "con la venia de la presidencia", "si el jurado lo permite", entre otras. A la vez, se constató la necesidad imponderable de ejercer la judicatura con elocuencia y de lograr un mayor dominio del lenguaje técnico, teniendo en cuenta la función retórica del lenguaje jurídico.

Luego de realizados estos ejercicios extracurriculares de simulación de juicios, se constató un comportamiento favorable del indicador relativo al nivel de conocimiento de los estudiantes sobre el sistema judicial, pues no solo se implicaron los que participaron activamente, sino el resto que asistió como oyente, incluso los estudiantes de años inferiores. El nivel de satisfacción de los profesores, estudiantes y juristas litigantes con la ejecución de los juegos de roles, de acuerdo con las entrevistas demostró que ha aumentado respecto a periodos anteriores. De hecho, el nivel de contribución de dicha propuesta, según el total de estudiantes interrogados, en una escala de muy baja, baja, media, alta y muy alta, se comportó entre alta (25\%) y muy alta $(75 \%)$.

Ciertamente los tres ejercicios de simulación desarrollados, tanto al practicar el interrogatorio como al presentar los alegatos, marcaron pautas en el dominio de destrezas orales. El último de los juegos de roles desarrollado en 2019 sobre el Juicio del Moncada, al ser evaluado en una investigación precedente por Páez y Carballo (2000), se consideró que:

Una diferencia sustancial con respecto a los inicios de la investigación radica en que, después de la estrategia implementada, un $90 \%$ de los estudiantes considera trascendental el papel de la litigación en la formación del jurista y en el desarrollo de destrezas profesionales. (p. 19)

Los ejercicios simulados de roles litigantes demostraron la manifestación concreta de la oralidad como principio del procedimiento y a su vez la función retórica del lenguaje jurídico como expresión del uso oral. Su ejecución por parte de los 11 estudiantes de Derecho en 2017, los 22 que intervinieron en 2018 y los 15 que participaron en 2019, evidenció el desarrollo de competencias comunicativas, como la pragmática, la discursiva, la funcional y la sociolingüística.

La experiencia validada en la Universidad de Pinar del Río demuestra que la enseñanza y el aprendizaje de la oralidad reportan notables beneficios para el Derecho y su didáctica. Teniendo en cuenta que los juristas requieren destrezas específicas para la litigación oral, estas deben intencionarse desde la academia, habida cuenta de que las carencias comunicativas del abogado en el estrado se deben precisamente a deficiencias formativas precedentes de los estudios universitarios. De ahí la necesidad de desarrollar juegos de roles orales como métodos para potenciar un aprendizaje activo, consciente y desarrollador de la oralidad en el proceso formativo del jurista en la educación superior.

\section{Conclusiones}

La oralidad es una capacidad comunicativa, una forma de comunicación lingüística que reporta beneficios significativos a la ciencia jurídica. Su práctica es reconocida por los sistemas judiciales más avanzados y su abordaje teórico adquiere una nueva dimensión jurídica como principio sine qua non para el Derecho Procesal.

La introducción de la oralidad en el campo del Derecho es un aporte esencial del sistema de enjuiciar acusatorio, que adquiere una connotación 
contemporánea distintiva, en tanto es facilitadora del resto de los principios y las garantías del proceso. Su regulación jurídica explícita se evidencia en códigos procesales penales hispanos, como principio que favorece la celeridad del proceso y facilita la inmediación del juez con las partes litigantes en el denominado juicio oral y público.

En el escenario judicial, la oratoria forense implica una auténtica oralidad procesal desplegada en audiencias públicas por parte de los juristas litigantes, quienes exponen una teoría del caso dirigida a convencer o persuadir a los jueces de la tesis que defienden mediante la argumentación oral. Y el alegato judicial, al ser un uso oral elaborado o formal, constituye, por antonomasia, la expresión jurídica más concreta de la oralidad.

En la Universidad de Pinar del Río, Cuba, durante el periodo 2017-2019 se desarrollaron ejercicios simulados de juicios orales en la carrera de Derecho, como vía para favorecer la profesionalización de la enseñanza. La experiencia fue valorada como positiva por parte de los sujetos implicados en su implementación, en especial por los propios estudiantes que fungieron como litigantes en los tres juegos de roles llevados a cabo, luego de lo cual se constató la conveniencia de potenciar la oralidad en la formación profesional del jurista.

La experiencia pedagógica detallada ha demostrado los aportes de los juegos de roles al aprendizaje práctico de la oralidad jurídica. Los tres ejercicios académicos favorecieron en los estudiantes la apropiación de roles como sujetos procesales (defensor, acusador o juez), mostrando evolución en la hermenéutica del lenguaje técnico-jurídico y en la asunción de expresiones que denotan cortesía en el estrado. En sentido general se lograron interacciones lingüísticas significativas durante la presentación de los alegatos judiciales como intervenciones orales formales.

Considerando la necesidad de preparar al estudiante de Leyes para la presentación de discursos orales en los tribunales, se deriva la propuesta de insertar conscientemente la oralidad en la enseñanza del Derecho, lo cual fue validado en la investigación al implementar métodos de enseñanza problémica como los juegos de roles, sin que ello excluya la posibilidad de emplear a posteriori nuevas propuestas didácticas sobre los usos orales.

\section{Reconocimientos}

El artículo se deriva del proyecto de innovación "Modelo de formación integral del profesional del Derecho" (PI-145), vigente durante el periodo 2017-2020 en la Universidad de Pinar del Río (Cuba). A su vez, resultados parciales de la investigación se obtuvieron gracias al financiamiento de la Asociación Universitaria Iberoamericana de Posgrado (AUIP), mediante una beca posdoctoral concedida en el año 2017, la cual estuvo tutelada por la doctora María Pilar Núñez Delgado, distinguida profesora de la Universidad de Granada (España), cuya asesoría resultó esencial para las indagaciones teóricas sobre la oralidad, las ciencias del lenguaje y su vinculación al Derecho.

\section{Referencias bibliográficas}

Abascal, M. (2004). La teoría de la oralidad. Andalucía: España: Universidad de Málaga.

Álvarez, C. M. (1999). Didáctica. La escuela en la vida. 3a. ed. La Habana: Editorial Pueblo y Educación.

Areta, M. (2007). Reflexiones sobre la presencia de lo oral en las declaraciones matrimoniales de finales del siglo XVI. Oralia. Análisis del Discurso Oral, 1, 317-332. Recuperado de https://dialnet.unirioja.es/ servlet/articulo? codigo $=2549200$

Baytelman, A. y Duce, M. (2004). Litigación penal y juicio oral. Santiago de Chile: Editorial del Fondo de Justicia y Sociedad.

Binder, A. (1993). Introducción al Derecho Procesal Penal. Buenos Aires: Ad-Hoc.

Cappelletti, M. (1972). La oralidad y las pruebas en el proceso civil. Trad. de S. Sentís Melendo. Buenos Aires: Jurídicas Europa-América. 
Casanueva, S. (2010). Juicio oral, teoría y práctica. México: Porrúa.

Chiovenda, G. (1977). Principios de Derecho Procesal. 3a. ed. Trad. de Casais. Madrid: Editorial Reus.

Couture, E. (1981). Fundamentos del Derecho Procesal Civil. Buenos Aires: De Palma.

Ferrajoli, L. (1995). Derecho y razón. Teoría del garantismo penal. Madrid: Trotta.

Gimeno, F. (1981). Fundamentos del Derecho procesal (Jurisdicción. Acción y proceso). Madrid: Civitas.

González, D. (1996). La oralidad como facilitadora de los fines, principios y garantías del proceso penal. Revista Cubana de Derecho, 11, 88-119.

Gutiérrez, Y. y Rosas, A. I. (2008). La oralidad en la escuela: algunas reflexiones. Hojas y Hablas, 5, 46-56.

Lomas, C. (2014). La educación lingüística, entre el deseo y la realidad: competencias comunicativas y enseñanza del lenguaje. Barcelona: Ediciones Octaedro.

Majmutov, M. I. (1983). La enseñanza problémica. La Habana: Editorial Pueblo y Educación.

Mendoza, J. (2013). El juicio oral en Cuba. La Habana: Unión Nacional de Juristas de Cuba.

Montero, J. (2006). La oralidad entre el mito y la realidad (o de la ideología autoritaria). Revista del Colegio de Abogados y Notarios de Guatemala, 52. Guatemala: Editorial Serviprensa.

Mortara, B. (1988). Manual de retórica. Madrid: Cátedra.

Narváez, J. R. (2019). Metodología crítica para la investigación científica del derecho. Revista Pedagogía Universitaria y Didáctica del Derecho, 6(2), 81-95. DOI: 10.5354/0719-5885.2019.55309

Nieva, J. (2010). Los problemas de la oralidad. Revista do Ministério Público do RS, 67, 237-257.

Núñez, M. P. (2003). Didáctica de la comunicación oral: Bases teóricas y orientaciones metodológicas para el desarrollo de la competencia discursiva oral en la educación obligatoria. Granada: Grupo Editorial Universitario.

Núñez, M. P. (2011). Espejos y ventanas: dimensiones de la oralidad en el ámbito educativo. Enunciación, 16(1), 136-150.
Núñez, M. P. y L. D. Páez (2018). Competencia oral, lenguaje jurídico y teoría de la argumentación. Revista Oralia. Análisis del Discurso Oral, 21(2), 343358. Recuperado de https://www.researchgate.net/ publication/330344930_Competencia_oral_lenguaje_juridico_y_teoria_de_la_argumentacion

Olson, D. y Torrance, N. (comps.) (1995). Cultura escrita y oralidad. Barcelona: Gedisa.

Ong, W. (1996). Oralidad y escritura. Tecnologías de la palabra. México: Fondo de Cultura Económica.

Ossorio, M. (2000). Diccionario de Ciencias Jurídicas, Políticas y Sociales. 27a. ed. Buenos Aires: Editorial Heliasta.

Páez, L. D. (2014). Modelo de formación de estudiantes de Derecho para la litigación. Una estrategia para su implementación en la Universidad de Pinar del Río. [Tesis de maestría]. Universidad de Pinar del Río, Cuba. Recuperado de https://rc.upr.edu.cu/ jspui/handle/DICT/2375

Páez, L. D. y Díaz, T. (2016). La enseñanza del Derecho Procesal en Cuba: retos de la formación para la litigación. Revista Pedagogía Universitaria, 21(3), 23-35.

Páez, L. D. y Carballo, A. (2020). Enseñar a litigar en Derecho: una experiencia práctica en la Universidad de Pinar del Río. Cuaderno de Pedagogía Universitaria, 17(33), 17-28. DOI: 10.29197/cpu. v17i33.370

Prieto, M. (2001). El Derecho como ciencia. Cuba Siglo XXI. Política. [En línea]. Recuperado de https://www. nodo50.org/cubasigloXXI/politica/prieto4_301001. htm

Prieto-Castro, L. (1964). Derecho Procesal Civil. Madrid: Editorial Revista de Derecho Privado.

Pujol, M. (1992). Algunas reflexiones sobre la didáctica de la lengua oral. Comunicación, Lenguaje y Educación, 16, 119-126.

Rivero, D. (2014). Estudios sobre el Proceso Penal. La Habana: Ediciones ONBC.

Rodríguez, D. C. y Giraldo, M. C. (2019). Una propuesta para enseñar argumentación desde el modelo de Biggs. Enunciación, 24(2), 199-210. DOI: $10.14483 / 22486798.14444$ 
Suñez, Y., D. González y W. Urra. (2012). La oralidad en la fase intermedia del proceso penal cubano. Revista Contribuciones a las Ciencias Sociales [En línea]. Recuperado de http://www.eumed.net/rev/ cccss/20/tmd.html

Valle, A. (2009). Algunos modelos importantes en la investigación pedagógica I. La Habana: Editorial ICCP.
Velazco, M. (2015). La modernización del procedimiento agrario y su posible incidencia en $\mathrm{Cu}$ ba. Revista de la Abogacía, Boletín ONBC, 53, 200-208. Recuperado de https://www.onbc.cu/ uploads/media/page/0001/01/7c9af993b00eada2d632048522853e06079db7e6.pdf

Villabella, C. M. (2012). Investigación y comunicación científica en la Ciencia Jurídica. La Habana: Editorial Universitaria Félix Varela.

\section{(c) (1) $\$($ )}

